\title{
Radio-echo sounding and waveform modeling reveal abundant marine ice in former rifts and basal crevasses within Crary Ice Rise, Antarctica
}

\section{Article}

*Now at Fluid Dynamics and Solid Mechanics Group, Los Alamos National Laboratory, Los Alamos, NM, USA.

Cite this article: Hillebrand TR, Conway $\mathrm{H}$, Koutnik M, Martín C, Paden J, Winberry JP (2021). Radio-echo sounding and waveform modeling reveal abundant marine ice in former rifts and basal crevasses within Crary Ice Rise, Antarctica. Journal of Glaciology 67 (264), 641-652. https://doi.org/10.1017/ jog.2021.17

Received: 29 June 2020

Revised: 27 January 2021

Accepted: 28 January 2021

First published online: 5 March 2021

\section{Keywords:}

Antarctic glaciology; crevasses; ice rise; ice shelves; radio-echo sounding

Author for correspondence:

Trevor R. Hillebrand,

E-mail: trhille@lanl.gov
Trevor R. Hillebrand ${ }^{1, \star}$ (D), Howard Conway ${ }^{1}$, Michelle Koutnik ${ }^{1}$, Carlos Martín² (D), John Paden ${ }^{3}$ (D) and J. Paul Winberry ${ }^{4}$

${ }^{1}$ Department of Earth and Space Sciences, University of Washington, Seattle, WA, USA; ${ }^{2}$ British Antarctic Survey, Cambridge, UK; ${ }^{3}$ Center for the Remote Sensing of Ice Sheets, University of Kansas, Lawrence, KS, USA and

${ }^{4}$ Department of Geological Sciences, Central Washington University, Ellensburg, WA, USA

\section{Abstract}

Crary Ice Rise formed after the Ross Ice Shelf re-grounded $\sim 1$ kyr BP. We present new ice-penetrating radar data from two systems operating at center frequencies of 7 and $750 \mathrm{MHz}$ that confirm the ice rise is composed of a former ice shelf buried by subsequent accumulation. Stacks of englacial diffraction hyperbolas are present almost everywhere across the central ice rise and extend up to $\sim 350 \mathrm{~m}$ above the bed. In many cases, bed reflections beneath the diffraction hyperbolas are obscured for distances up to $1 \mathrm{~km}$. Waveform modeling indicates that the diffraction hyperbolas are likely caused by marine ice deposits in former basal crevasses and rifts. The in-filling of rifts and basal crevasses may have strengthened the connection between the ice rise and the surrounding ice shelf, which could have influenced local and regional ice dynamics. Three internal reflection horizons mark the upper limit of disturbed ice and diffraction hyperbolas in different sections of the ice rise, indicating at least three stages of flow stabilization across the ice rise. A surface lineation visible in MODIS imagery corresponds spatially to deepening and strong deformation of these layers, consistent with the characteristics of former grounding lines observed elsewhere in Antarctica.

\section{Introduction}

Ice rises are locally grounded regions within ice shelves that provide a stabilizing resistance to ice flow (Thomas and others, 1979; MacAyeal and others, 1987; Favier and Pattyn, 2015; Matsuoka and others, 2015). Model experiments have shown that ice rises can stabilize grounding lines in otherwise unstable configurations (Goldberg and others, 2009). However, ice rise formation and evolution are currently poorly understood (Matsuoka and others, 2015), and many ice rises are too small to be resolved by continent-scale ice-sheet models. Observation-based understanding of ice rise processes is necessary to accurately parameterize them in ice-sheet models. Here we present new observations that provide insight into the formation and evolution of an ice rise.

Crary Ice Rise (CIR) is a grounded promontory within the Ross Ice Shelf (Fig. 1) that provides roughly half the resistance to flow from Whillans and Mercer Ice Streams, and reduces ice-shelf spreading rates by an order of magnitude (MacAyeal and others, 1987, 1989; Still and others, 2018). Along with Roosevelt Island and Steershead Ice Rise, it is one of only three ice rises identified within the Ross Ice Shelf (Matsuoka and others, 2015). Streak lines and rifts visible on the surface of the ice shelf indicate the ice rise has existed for at least 700 years (Fahnestock and others, 2000). Borehole thermometry data and thermal modeling indicate that the ice rise formed in at least two stages, when the ice shelf re-grounded $\sim 1 \mathrm{kyr}$ and $\sim 600 \mathrm{yr}$ BP (Bindschadler and others, 1990). It is not known whether the re-grounding was a result of increased discharge from the Siple Coast ice streams (Bindschadler, 1993), isostatic rebound (e.g. Kingslake and others, 2018) or a combination of the two. While two stages have been identified in the evolution of CIR (Bindschadler and others, 1990), the Siple Coast ice streams have stagnated and reactivated multiple times over the last millennium (Catania and others, 2012). Thus, it is likely that the formation and evolution of CIR was more complex than has been demonstrated to this point. Here we use new ground-based radio-echo sounding data to map englacial structures and stratigraphy to interpret the dynamics of grounding and subsequent evolution of the ice rise. We then model radar waveforms to test hypotheses about the origin of the radar-detected structures we observe.

\section{Data and methods}

\subsection{Radar systems}

Two radar systems were used to map englacial structures, internal layers, and ice thickness at CIR in November and December 2015. We used the University of Washington (UW) highfrequency, mono-pulse system with resistively loaded dipole antennas operating at the center frequency of $7 \mathrm{MHz}$; range resolution is $\sim 6 \mathrm{~m}$ in ice (1/4 wavelength). The transmitter and receiver were towed inline ( $\mathrm{p}$-polarized) behind a skidoo; the receiver was triggered by the airwave from the transmitter. The airwave causes signal saturation in the upper $0.15 \mu \mathrm{s}(\sim 25 \mathrm{~m})$ 


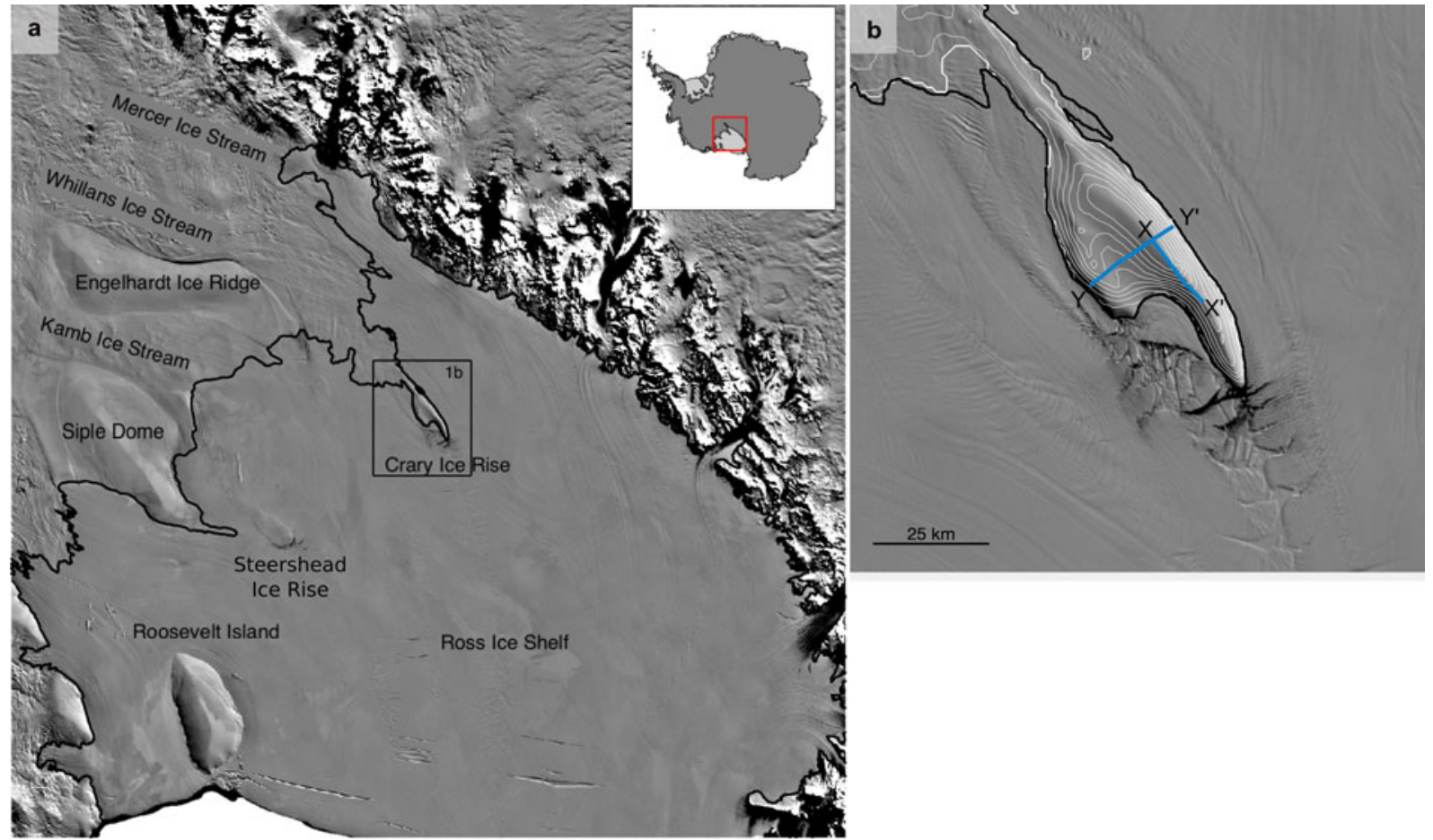

Fig. 1. Location of Crary Ice Rise in the Ross Embayment of Antarctica. Tracks of the two main radar surveys discussed are shown in Figure 1b. Annotated echograms from the surveys are shown in Figures 2, 3. The $10 \mathrm{~m}$ elevation contours from Fretwell and others (2013) are shown in white to give an indication of flow direction for grounded ice. Maps generated using the Antarctic Mapping Toolbox for MATLAB (Greene and others, 2017).

Table 1. Dielectric properties of the different materials used in waveform modeling

\begin{tabular}{lcc}
\hline Material & Relative permittivity & $\begin{array}{l}\text { Conductivity } \\
\left(\mathrm{S} \mathrm{m}^{-1}\right)\end{array}$ \\
\hline Glacier ice & 3.2 & $7.0 \times 10^{-5}$ \\
Marine ice & 3.4 & $5.7 \times 10^{-4}$ \\
Brine-rich ice & 4.1 & $0.01,0.1$ \\
Frozen till (40\% groundwater ice) & 2.9 & $3.4 \times 10^{-4}$ \\
Unfrozen bedrock & 12 & 0.0048
\end{tabular}

Values are from Christianson and others (2016), except for brine-rich ice, which uses the dielectric properties of sea ice from Morey and others (1984).

of the received records. Each record consists of 1024 stacked waveforms to improve the signal-to-noise ratio. Positions and elevations of records were located using GPS with average spacing along the track of $2.7 \mathrm{~m}$. Data processing includes bandpass filtering, and accounting for the distance between the transmitter and receiver $(39 \mathrm{~m})$. We present unmigrated data here because the diffraction hyperbolas form a central part of our analysis. At $7 \mathrm{MHz}$, internal reflections below the firn are caused primarily by contrasts in electrical conductivity (Fujita and others, 1999). Englacial reflections, measured as a function of radar two-way travel time, were converted to a depth below the surface using a wave

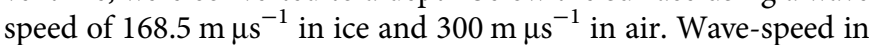
the firn was estimated by calculating the dielectric constant using an empirical depth-density model (Herron and Langway, 1980) and Looyenga's mixing equation (Looyenga, 1965).

Uncertainty in the depth to a nadir reflecting layer arises from uncertainty in the wave speed in ice $\left(\sim 1 \mathrm{~m} \mu \mathrm{s}^{-1}\right.$, which corresponds to $0.6 \%$ of the depth to the reflector), and from ambiguity in picking the two-way travel time $(0.01 \mu \mathrm{s}$ or $\sim 1 \mathrm{~m}$ in ice); total uncertainty for a reflector at $500 \mathrm{~m}$ depth is $\sim 4 \mathrm{~m}$. However, mono-pulse radars have significant gain from side lobes in the radiation pattern in off-nadir directions, both fore and aft and either side of the transmitter-receiver pair (Arcone, 1995; Jacobel and others, 2014). A consequence is that strong returns from targets within the side lobes have arrival times greater than nadir reflections; our $7 \mathrm{MHz}$ profiles on CIR often show strong reflections that appear up to $100 \mathrm{~m}$ below the basal reflector, which complicates interpretation.

We also used an ultra-high-frequency (UHF) pulsed chirp radar developed by the Center for the Remote Sensing of Ice Sheets (CReSIS), operating over $300 \mathrm{MHz}$ of bandwidth centered at $750 \mathrm{MHz}$, with a range resolution of $43 \mathrm{~cm}$ in ice (Lewis, 2015; Lewis and others, 2015). A $600-900 \mathrm{MHz}$ linear FM chirp is transmitted at a $50 \mathrm{kHz}$ pulse repetition frequency and directly captured using a 1 giga-sample per second analogue-to-digital converter. An eight-element wideband dipole antenna array is used with a power combiner to create a directive beam pointed toward nadir (Rodriguez-Morales and others, 2014). The $1 \mu \mathrm{s}$ pulse duration results in signal saturation in the upper $\sim 90 \mathrm{~m}$, but the UHF yields enhance sensitivity to dielectric changes deeper in the ice. Transmission power was $5 \mathrm{~W}$. Surface topography and location were recorded with GPS. Data were migrated using a Fourier transform method (Leuschen and others, 2000) and processed using the standard CReSIS toolbox (https://ops. cresis.ku.edu/wiki/index.php/Main_Page).

The lower frequency of the UW system enables improved layer coherence and reduced radar clutter, while the CReSIS system has enhanced range resolution. The UW system is more robust for travel over rough terrain and during high winds, typical of conditions on CIR, so surveys with the CReSIS system were made at high spatial density in the vicinity of camp.

\subsection{Waveform modeling}

We use the open-source waveform modeling software gprMax (Warren and others, 2016) to test hypotheses for the origin of the observed englacial structures observed across CIR. gprMax solves Maxwell's equations in two or three dimensions using the Finite-Difference Time Domain method. We use the default setting for absorbing boundary conditions. We model the 7 $\mathrm{MHz}$ waveforms in 2D with a Hertzian dipole point source and a receiver separated by $39 \mathrm{~m}$. Modeling the $750 \mathrm{MHz}$ waveforms 


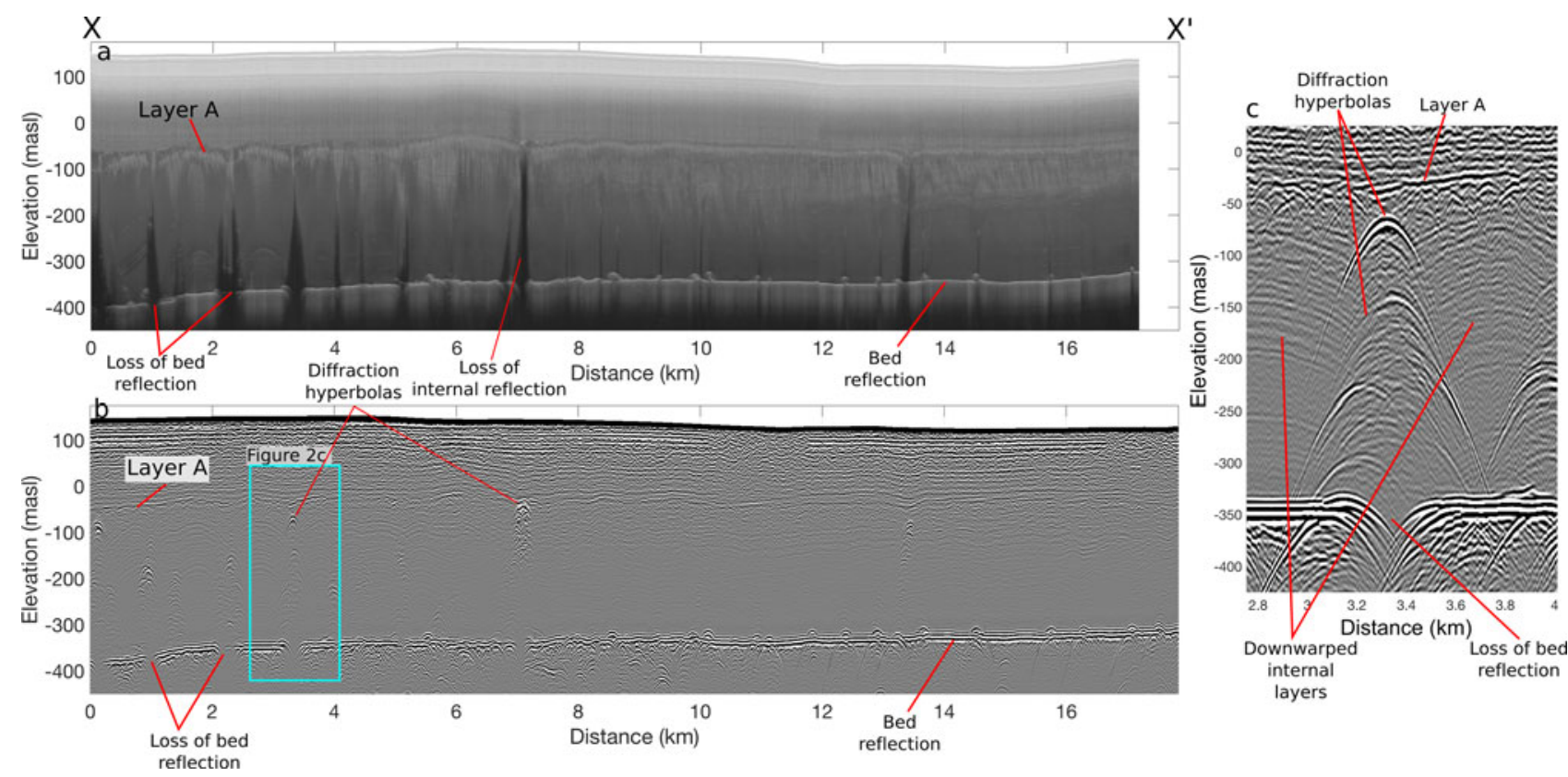

Fig. 2. Transect $X-X^{\prime}$ along the crest of the main ridge of the ice rise using radars operating at $750 \mathrm{MHz}$ (a) and $7 \mathrm{MHz}$ (b). Both echograms are corrected for surface topography. The $750 \mathrm{MHz}$ data were processed using the CReSIS toolbox. The $7 \mathrm{MHz}$ data are not migrated so as to reveal the diffraction hyperbolas. Layer A and several examples of diffraction hyperbolas and loss of bed or internal reflections are labeled. (c) Enlarged section of profile X-X', shown by the cyan box in (b). Note the down-warping of internal layers toward the stacks of diffraction hyperbolas, accompanied by loss of bed reflection.

is computationally impractical due to the high resolution required for the short wavelength of the UHF system, and the $\mathrm{km}^{2}$-scale model domain. Dielectric properties used in the model experiments are given in Table 1.

\section{Radar-detected englacial structures}

Radar profiles at 750 and $7 \mathrm{MHz}$ along $\mathrm{X}-\mathrm{X}$ ' (Fig. 2) reveal a highly reflective and spatially continuous layer (hereafter referred to as Layer A) at both frequencies. Internal horizons are visible at depths below Layer A at $7 \mathrm{MHz}$, but only rarely at $750 \mathrm{MHz}$, likely because of the high sensitivity of UHF systems to scattering (Lewis and others, 2015) and steeply dipping layers (Holschuh and others, 2014). Numerous stacks of diffraction hyperbolas extend up to $300 \mathrm{~m}$ above the bed, where total ice thickness is $\sim 500 \mathrm{~m}$. Internal reflection horizons between the stacks of diffraction hyperbola are often warped downwards, forming arcs with amplitudes of up to $40-50 \mathrm{~m}$ (Fig. 2c). Many of these diffraction hyperbolas intersect Layer $\mathrm{A}$ and overlie locations where the bed echo is obscured.

Radar profiles along Y-Y' (Fig. 3) reveal four distinct zones (labeled Zones 1-4). Zone 1 crosses the lower (grid southwest) ridge of the ice rise. The deepest continuous layer in Zone 1 (at $\sim 100 \mathrm{~m}$ depth, which we call Layer C) marks a transition from conformal layers to disturbed ice. We infer that Layer $\mathrm{C}$ represents a transition from shelf or streaming flow to divide flow at the lower ridge. Layer A is faintly visible in the 750 $\mathrm{MHz}$ data in part of Zone 1 where it is highly deformed and discontinuous. In contrast to other zones, Layer A does not mark the uppermost limit of diffraction hyperbolas in Zone 1; hyperbolas at $\sim 3 \mathrm{~km}$ along Y-Y' extend $\sim 75 \mathrm{~m}$ above Layer A. Although the tops of the strong diffraction hyperbola in this zone extend $\sim 275 \mathrm{~m}$ above the bed, the bed reflection is reduced but not completely obscured. While strong mid-depth diffraction hyperbolas are less abundant than elsewhere, hyperbolas near the bed are more numerous.

In Zone 2, Layer $\mathrm{C}$ is clearly visible, but does not represent the deepest undisturbed ice. A strongly reflective layer $\sim 30 \mathrm{~m}$ deeper than Layer $\mathrm{C}$ represents the deepest undisturbed ice in Zone 2 (Fig. 3). The pattern of deformation of Layer B is similar to that of Layer A, but it is more muted and is not punctuated by numerous diffraction hyperbolas as is Layer A. This suggests that Layers A and B experienced a similar history of deformation, but Layer B was not subjected to the same process that caused the diffraction hyperbolas. Layer B terminates at a stack of diffraction hyperbolas at $\sim 6 \mathrm{~km}$ along $\mathrm{Y}-\mathrm{Y}$, which coincides with the transition where Layer A begins to be coincident with the upper limit of diffraction hyperbolas. Layer A does not appear brighter than others in the $7 \mathrm{MHz}$ data in this zone, but it is clearly discernable in the $750 \mathrm{MHz}$ data. Multiple stacks of diffraction hyperbolas extend up to $\sim 250 \mathrm{~m}$ above the bed and often obscure the bed reflection.

In Zone 3, an off-nadir reflection from a seismic shot-hole that we drilled at the crest of the ridge is visible in the $7 \mathrm{MHz}$ data. While the seismic shot-holes only reached a depth of $\sim 40 \mathrm{~m}$, this reflection appears deeper because it is off-nadir. The layers above Layer A are relatively undisturbed. Below Layer A, another strong reflection intersects with the shot-hole reflection, which is from off-nadir reflections from the same features that cause the englacial diffraction hyperbolas. The amplitude of the reflection from Layer A is larger than it is in Zone 2 and the layer is less deformed. On the grid northeast side of the ridge, a single stack of hyperbolas that intersects Layer A blocks the bed echo. Deep reflectors with an apparent dip of $\sim 10^{\circ}$ downwards to the bed are evident between 14 and $16 \mathrm{~km}$ in Zone 3 . We interpret these to be the same as the features that caused the strong diffraction hyperbolas elsewhere, but they have been sheared due to ice flow since the time of grounding. These dipping reflectors do not block the bed echo. Two layers below Layer A are visibly offset in the $750 \mathrm{MHz}$ data across these dipping reflectors. Directly beneath the divide of the ridge ( $\sim 16 \mathrm{~km}$ in $\left.\mathrm{Y}-\mathrm{Y}^{\prime}\right)$, a deep reflector subparallel to the bed overlies a region of very faint bed echo.

In contrast to other zones, Zone 4 is mostly free of diffraction hyperbolas and the bed reflection is strong. Layers $\mathrm{A}, \mathrm{B}$ and $\mathrm{C}$ are all visible in the $7 \mathrm{MHz}$ data; Layer $\mathrm{A}$ is visible at both 7 and 750 $\mathrm{MHz}$. All three of these layers are undisturbed and conformal 


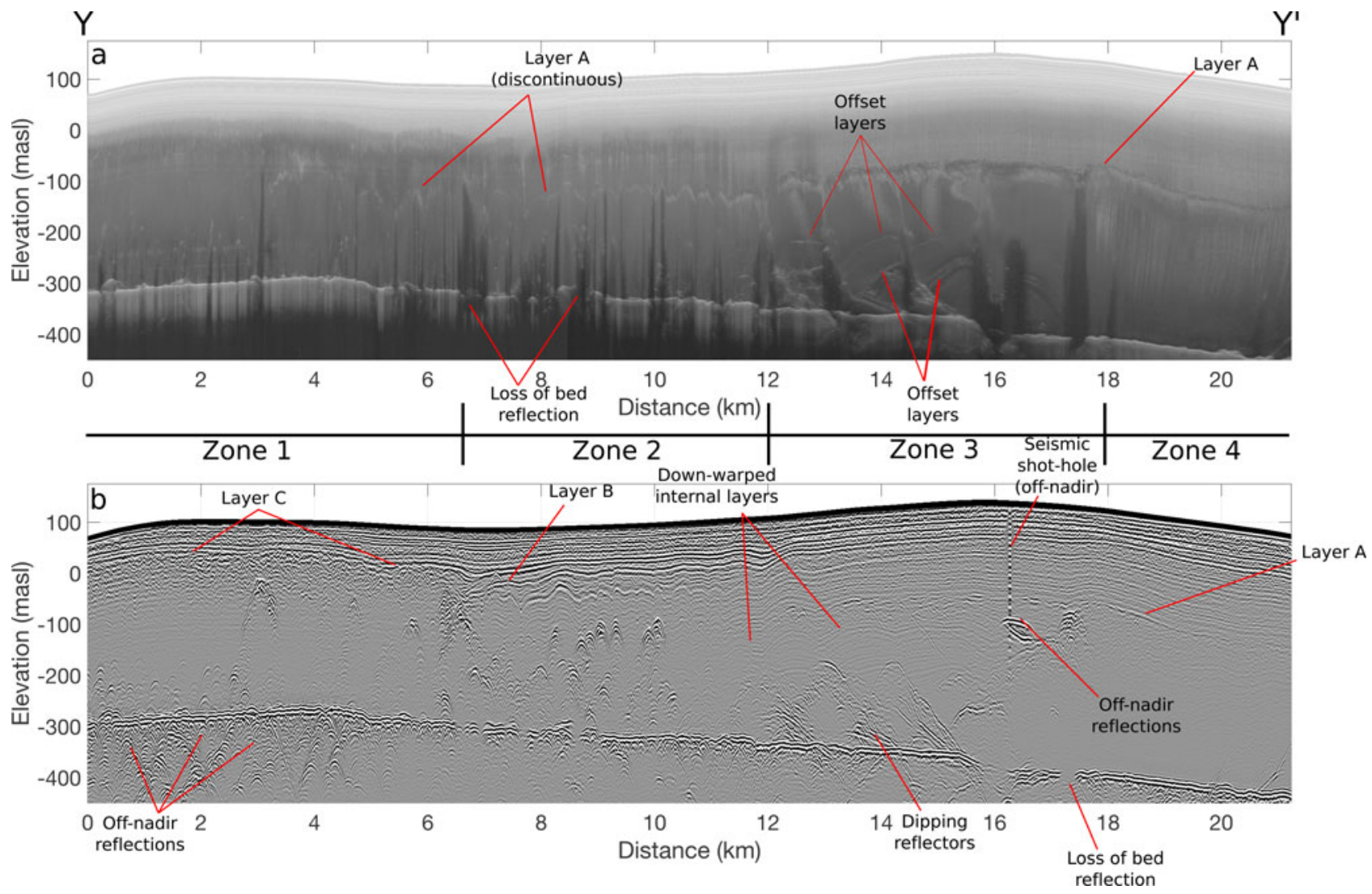

Fig. 3. Transect $Y-Y^{\prime}$ across the ice rise using $750 \mathrm{MHz}$ (a) and $7 \mathrm{MHz}$ (b). Both echograms are corrected for surface topography. The near surface reflection near the divide visible in the $7 \mathrm{MHz}$ data is from a seismic shot hole. Details of four distinct structural zones, labeled zones 1 through 4 are discussed in the text.

with layers above and below. Noteworthy features in Zone 4 are dipping reflectors that intersect with the bed and lean toward the ice shelf (20-21 km in Y-Y'). We interpret these to be basal crevasses formed slightly inland of the grounding-line of CIR.

Figure 4 shows three additional profiles surveyed parallel to Y-Y' at $750 \mathrm{MHz}$. These show more frequent loss of bed echo and substantial deformation of internal layers in the central plain of the ice rise compared to the grid northeast flank of the main ridge. Obscured bed reflection beneath the diffraction hyperbolas and steeply dipping deep reflectors is a characteristic feature in Zone 3. A linear feature visible in the $125 \mathrm{~m}$ resolution MODIS imagery (Haran and others, 2014) intersects the modern grounding line near the rifted zone in the ice shelf downstream of the ice rise, and trends parallel with the main ridge crest (shown in Figs 1 and 4). The lineation marks a break in slope in the Reference Elevation Map of Antarctica (REMA) DEM (Howat and others, 2019) and also marks (i) the onset of high-frequency deformation and a general deepening trend of Layer A to the grid southwest, and (ii) the boundary of dipping reflectors that intersect the bed and divide the offset layers shown in Figure 4a. Upstream (grid northeast) of the surface lineation in Figure $4 \mathrm{~d}$ is the largest region of lost bed reflection, where the bed echo is lost for a length of $\sim 1.5 \mathrm{~km}$.

\section{Interpretation of radar-detected Layers A, B and C}

Layers $\mathrm{A}, \mathrm{B}$ and $\mathrm{C}$ each mark the transition from undisturbed, conformable layering to disturbed ice containing numerous diffraction hyperbolas over different sections of CIR (Figs 3,4). We interpret the ice above these layers to be derived from local accumulation, while the disturbed ice below was formerly floating or fast flowing. This is consistent with the observations of similar reflection horizons within the modern Ross Ice Shelf (Tinto and others, 2019; Das and others, 2020) and the Brunt Ice Shelf (King and others, 2018). We interpret each of these layers to represent separate grounding or basal-freezing events: Layer A represents the grounding of the main (grid northeast) ridge of the ice rise; Layer $\mathrm{B}$ represents the grounding or stagnation of fast flow in the central plain; and Layer $\mathrm{C}$ represents the final grounding event at the shallower (grid southwest) ridge. These events are depicted schematically in Figure 5. This supports the sequence of events outlined by Bindschadler and others (1990), but also adds a separate event in which the central area of the ice rise grounded or stagnated after the main ridge, but before the shallow ridge. It is likely that these radar data hold clues to more stages of evolution that we have not identified.

The depth of Layer A increases across the surface lineation visible in the MODIS imagery (Haran and others, 2014) (Fig. 4). Several kilometers downslope (grid southwest) of the lineation, it becomes highly deformed with the amplitudes of $\sim 60 \mathrm{~m}$ over short distances. The deepening and increased deformation of Layer A with respect to the surface lineation is consistent with the hypothesis that the surface lineation delineates a former grounding line. The stratigraphic sequence is similar to that observed in the flat-ice terrain between Engelhardt Ice Ridge and Kamb Ice Stream, which has been interpreted to be a relict grounding line (Catania and others, 2006).

\section{Origin of diffraction hyperbolas and waveform model results}

Stacks of diffraction hyperbolas are prominent and ubiquitous internal structures in the central section of CIR. The bed reflections beneath the largest stacks are often $30-50 \mathrm{~dB}$ weaker than nearby reflections that are not beneath the hyperbolas (Fig. 6). Such strong attenuation of bed reflections is not normally 

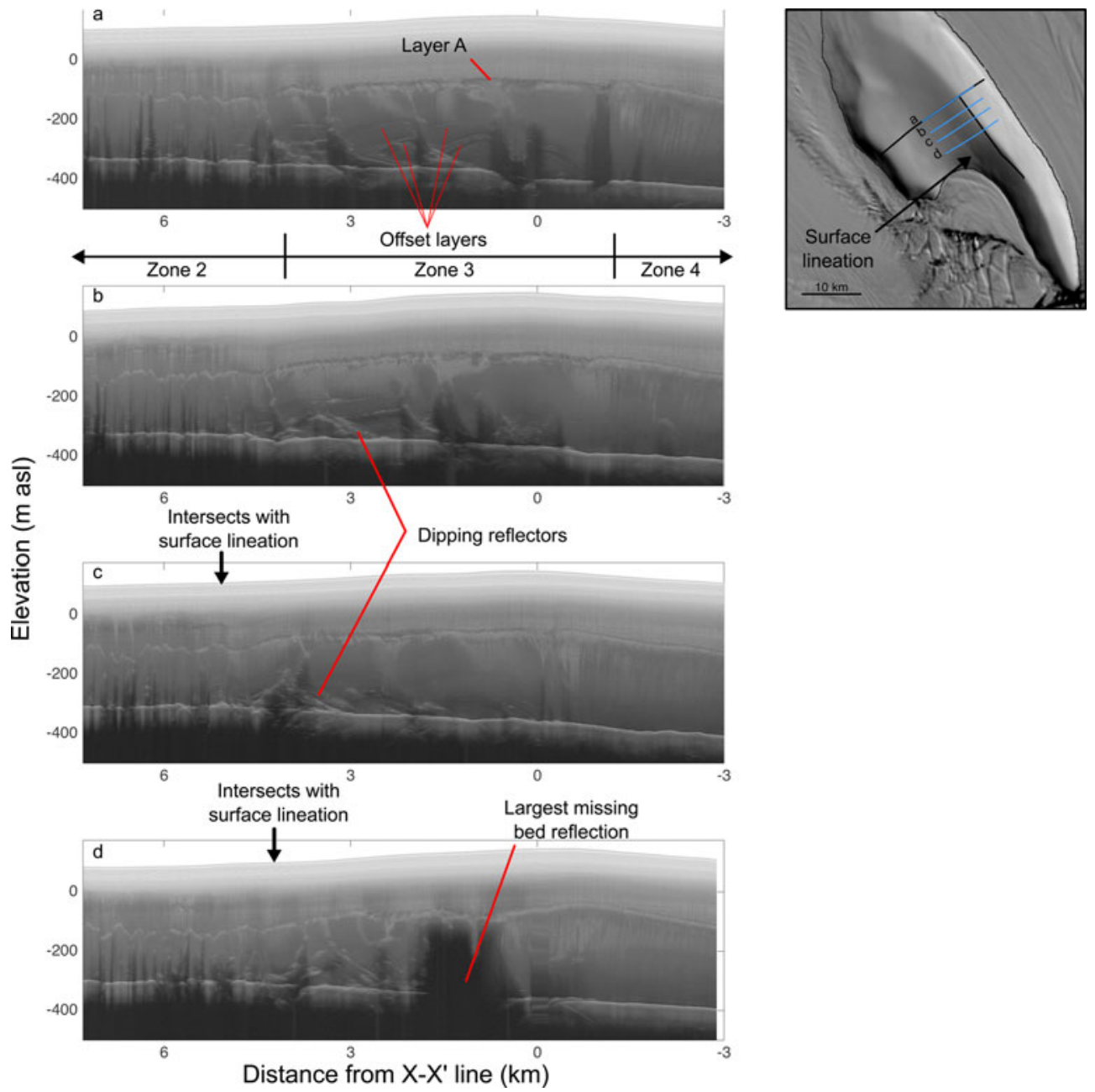

Fig. 4. The $750 \mathrm{MHz}$ radar profiles across the main ridge of the ice rise, showing the distribution of basal reflectors and the loss of bed reflection on the inner flank of the ice rise. Top to bottom profiles correspond to top to bottom tracks on the map. Distance on horizontal axis is relative to the X-X' profile, shown in black on the map, with negative distances corresponding to the shelf-proximal (grid northeast) side of the main ridge. Panel (a) shows a sub-section of $Y$ - $Y$ ' (Fig. 3). Profiles in panels (c) and (d) intersect a visible surface lineation marked on the map; intersection locations are denoted by black arrows on each profile.

found within grounded ice, but since CIR likely formed from re-grounding of the Ross Ice Shelf (Bindschadler and others, 1990), it is likely that these features are due to processes within the former ice shelf. Two processes within ice shelves have been demonstrated to attenuate radar waves: marine ice accretion and lateral brine infiltration. Marine ice has been observed in presentday rifts and crevasses around Antarctica (Khazendar and Jenkins, 2003; Jansen and others, 2013; Kulessa and others, 2014; Arcone and others, 2016), and its occurrence often obscures radio echoes from the bases of ice shelves. Concentrated brine pockets caused by lateral infiltration of seawater from rifts along firn/ice horizons are observed in the McMurdo Ice Shelf today (Morse and Waddington, 1994; Grima and others, 2016; Campbell and others, 2017). While the presence of either brine layers or marine ice would suggest past rifting of the ice that now forms CIR, establishing the englacial composition is important for evaluating the evolution of the ice rise and the ice shelf. For example, brine layers change the temperature, density and chemistry of the firn, but have little impact on the dynamics of the ice shelf (Thomas, 1975). In contrast, large deposits of soft marine ice inhibit fracture propagation, allow increased internal deformation and strengthen the ice shelf (e.g. Khazendar and others, 2001; Kulessa and others, 2014, 2019), and thus could have played an important role in the formation of CIR.

We use the gprMax waveform model (Warren and others, 2016) to test these hypotheses: radar attenuation is caused by accreted marine ice in former basal crevasses and/or rifts (H1); and radar attenuation is caused by pockets of brine trapped within the ice at the former firn-ice transition $(\mathrm{H} 2)$. Studies of brine infiltration layers have been conducted in areas where brine is actively entering an ice shelf (e.g. Grima and others, 2016; Campbell and others, 2017), or recharging from groundwater into englacial systems (Badgeley and others, 2017), but we are not aware of studies that have detected ancient brine pockets that are frozen and disconnected from the source, which could have very different dielectric properties from actively percolating liquid brine. Thus, we assume an effective dielectric constant of 4.1, calculated using Looyenga's mixing formula (Looyenga, 1965 ) for ice with $4.5 \%$ seawater inclusions by volume, which is a maximum estimate for brine concentration in a flooded firn layer (Thomas, 1975). This dielectric constant is similar to that of sea ice containing brine inclusions (Morey and others, 1984). The conductivity of the brine layer is much more difficult to estimate because it depends both on whether the brine is at the percolation threshold (Lux, 1993) (i.e. if an electrical pathway connects all parts of the brine pocket), and on the chemistry of the brine. Thus, we assume the conductivity of the layer is also similar to that of sea ice with brine inclusions, which ranges from $\sim 0.01$ to $0.1 \mathrm{~S} \mathrm{~m}^{-1}$ (Morey and others, 1984).

Due to the large number of unknowns and the wide range of possible geometries, we take an ensemble approach to modeling the radar signatures of the englacial structures in order to 
Ice shelf grounds

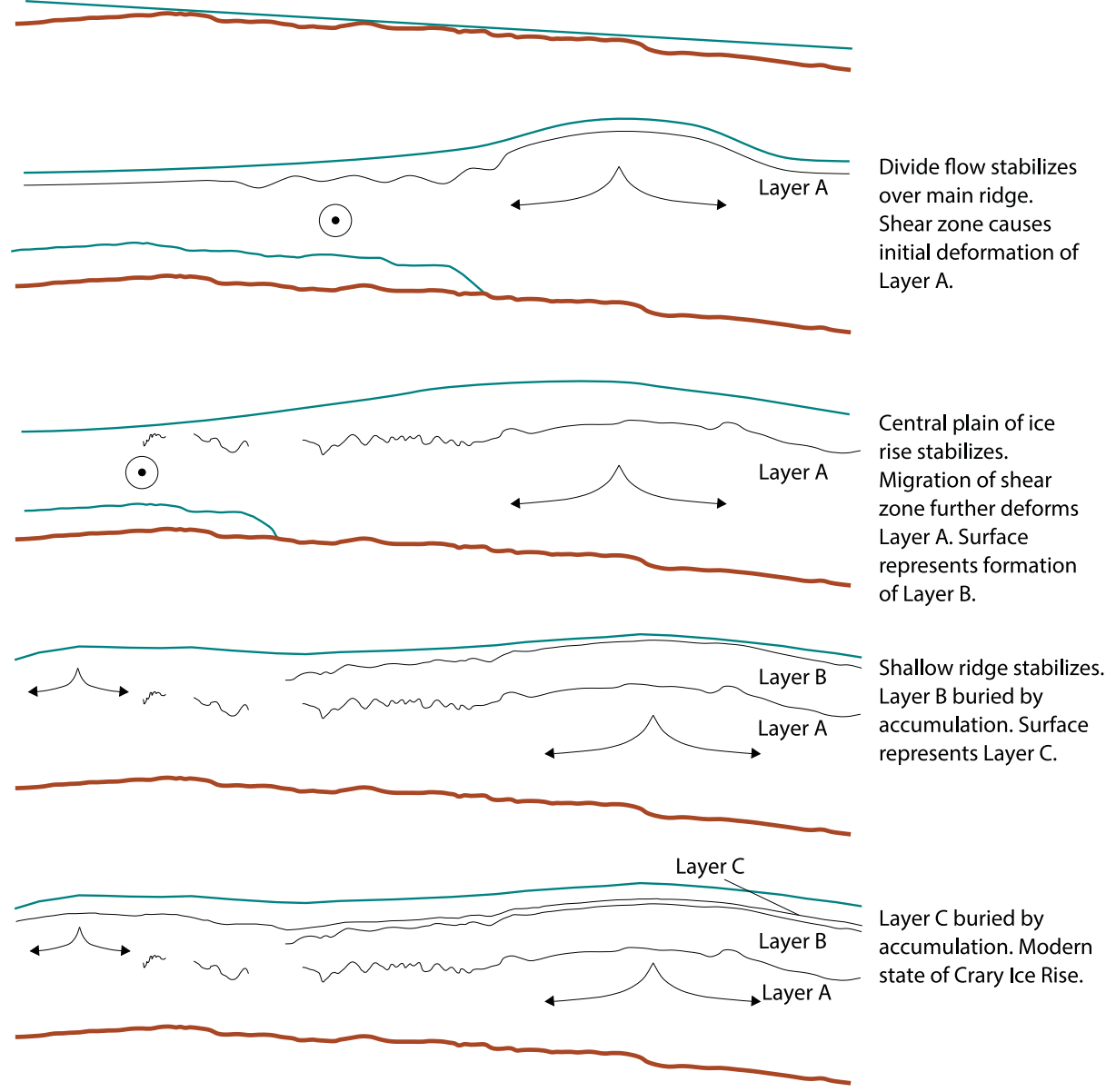

Fig. 5. Interpretation of Layers A, B and C in terms of the evolution of Crary Ice Rise. Arrows represent schematic flow patterns. Note that there are likely intermediate stages that are not captured by our analysis.

understand how bed echoes may be attenuated or lost completely. Our ensemble consists of 28 members and one control simulation with no brine layer and no marine ice layer. We model vertical brine layer thicknesses of 1 and $10 \mathrm{~m}$, which we assume to be a reasonable range based on observations of active brine layers (Campbell and others, 2017). We use brine layer conductivities of 0.1 and $0.01 \mathrm{~S} \mathrm{~m}^{-1}$, in order to span the range of sea-ice conductivities (Morey and others, 1984). Modeled horizontal layer widths are 10, 50, 100 and $200 \mathrm{~m}$ (for both brine and marine ice), to match observed loss of bed echo. We use vertical marine ice thicknesses of 10, 150 and $305 \mathrm{~m}$ to span the possible range from a deposit at the top of a fracture to complete filling of the fracture. In all runs, the top of the brine or marine ice layer lies $305 \mathrm{~m}$ above the bed ( $150 \mathrm{~m}$ below the surface). Total ice thickness (including a $24 \mathrm{~m}$ firn column) is $455 \mathrm{~m}$ in all runs, which is an intermediate value for ice thicknesses at CIR. The ice-sheet bed is treated as a $10 \mathrm{~m}$-thick layer of frozen till overlying unfrozen bedrock, based on observations of till clasts frozen to the drill during hot water drilling in the 1980s (Bindschadler and others, 1990). The model domain is $1200 \mathrm{~m}$ wide by $600 \mathrm{~m}$ tall and is sampled by 119 different transmitter-receiver $(39 \mathrm{~m}$ separation) positions at intervals of $10 \mathrm{~m}$. Horizontal and vertical model resolution is $0.8 \mathrm{~m}$. Model geometry is shown in Figure 7. Dielectric properties of the modeled materials are given in Table 1.

Results of the model ensemble show that reflector composition (i.e. brine or marine ice), width and thickness all exert strong controls on the strength of the bed echo from the base of the ice rise. To calculate the return power attenuated by the brine or marine ice layer in each run, we averaged the bed return power beneath the layer over $50 \mathrm{~m}$ horizontally and $10 \mathrm{~m}$ vertically and subtracted off the average over the same area in the control run. These results are shown in Figure 8a. For a given layer width, the thickest marine ice layer $(305 \mathrm{~m})$ is always the strongest attenuator, followed by the $150 \mathrm{~m}$-thick marine ice layer. The $10 \mathrm{~m}$-thick marine ice layer is always the weakest attenuator. The relationship between layer properties and attenuation is less straightforward for the brine layers. For the $10 \mathrm{~m}$-thick brine layer, the two conductivity values result in similar attenuation values for layers $10-100 \mathrm{~m}$ wide, while the lower conductivity value results in stronger attenuation for $200 \mathrm{~m}$ wide layer. Layer thickness has a relatively small effect on bed return power attenuation for the more conductive brine layer, but a large effect for the less conductive brine layer. We find 11 cases that result in strong enough attenuation to explain the $>30 \mathrm{~dB}$ decrease in bed echo beneath diffraction hyperbolas in our radar data. This shows that the degree to which the bed echo is attenuated cannot be used to definitely determine whether the diffraction hyperbolas are caused by marine ice or brine layers.

Next, we examine return power as a function of depth to determine if the model can help distinguish between the cases that could explain the observed loss of bed echo. Figure $8 \mathrm{~b}$ shows the average return power (minus the control) over the 50 horizontal meters spanning the domain center as a function of depth for selected members of the ensemble; the full ensemble results are shown in Figure 10 in Appendix. We find two strong reflection multiples beneath the brine layers in all scenarios. A single strong reflection multiple is also apparent beneath the marine-ice layer, 

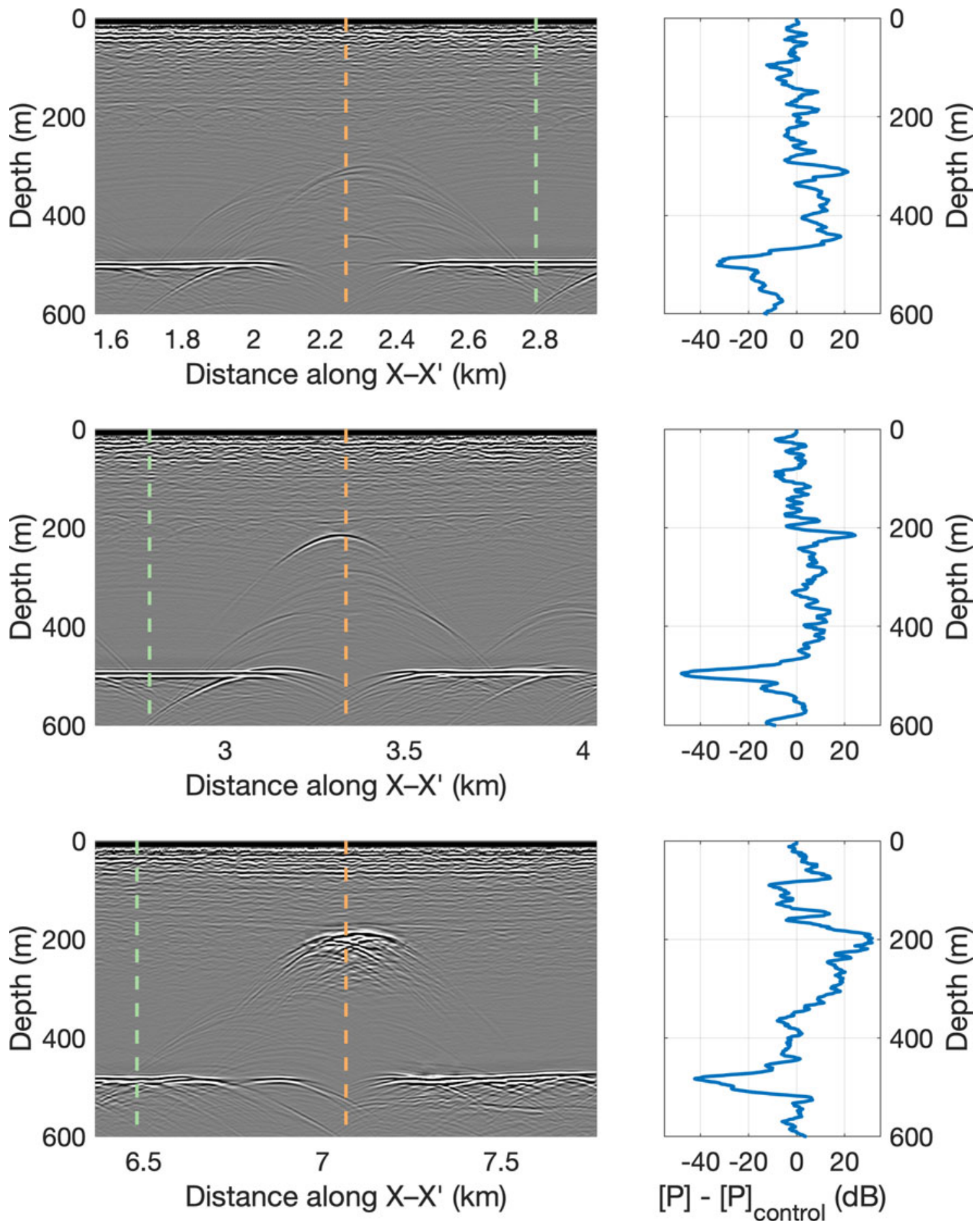

Fig. 6. Return power from $7 \mathrm{MHz}$ radar measurements along profile $\mathrm{X}-\mathrm{X}$ '. The blue curves in the right-hand column are calculated by averaging return power horizontally on a $25 \mathrm{~m}$-wide transect centered on the orange line in the left-hand column and subtracting off the same average around the green line. Curves represent a running average using a window of 10 vertical meters. Return power is calculated using the definition of Gades and others (2000).

but is $20-30 \mathrm{~dB}$ weaker than for brine layers of the same width. Our data do not show reflection multiples beneath the layers obscuring bed echoes, so we rule out the hypothesis that the bed echoes are obscured by brine layers. A rough or diffuse interface between the meteoric ice and marine ice would further decrease the strength of the multiple without significantly decreasing the attenuation. Such a rough and diffuse transition could result from the mélange of sea ice, icebergs, snow, and marine ice that often fill the tops of rifts (Fig. 9) (Rignot and MacAyeal, 1998; King and others, 2018). For a given width of modeled marine ice deposit, there is only a $2-5 \mathrm{~dB}$ difference in bed return power attenuation between layers $150 \mathrm{~m}$ thick and
$305 \mathrm{~m}$ thick (Fig. 8a); therefore, a layer $305 \mathrm{~m}$ thick that transitions gradually from locally accumulated glacier ice to marine ice over tens of meters would be almost as effective at obscuring the bed echo as the uniform $305 \mathrm{~m}$-thick layer we have modeled here, but the reflection at the upper boundary would be greatly diminished. A gradual transition would also explain the stacks of diffraction hyperbolas we observe in the radar data by providing many smaller dielectric contrasts that would each cause a reflection. A smooth transition over 1-10 $\mathrm{m}$ would have little effect on the reflectivity of the brine layer because these layer thicknesses are already very close to (or below) the $6 \mathrm{~m}$ range resolution of a $7 \mathrm{MHz}$ system. Therefore, we interpret the 
Fig. 7. Schematic of gprMax model geometry. Layer thickness, layer width and layer type (i.e. marine ice or brine) are variable model parameters. Here we show the model configuration for marine ice with width $=100 \mathrm{~m}$ and thickness $=150 \mathrm{~m}$. For the rift configuration, the layer reaches the bedrock (thickness = $305 \mathrm{~m}$ ); for the brine configuration, the layer is one to two orders of magnitude thinner than shown here. The top of the layer is always at the depth shown here. Transmitter and receiver are stepped across the domain from left to right at $10 \mathrm{~m}$ intervals. All domain boundaries are treated as perfect absorbers of transmitted energy.

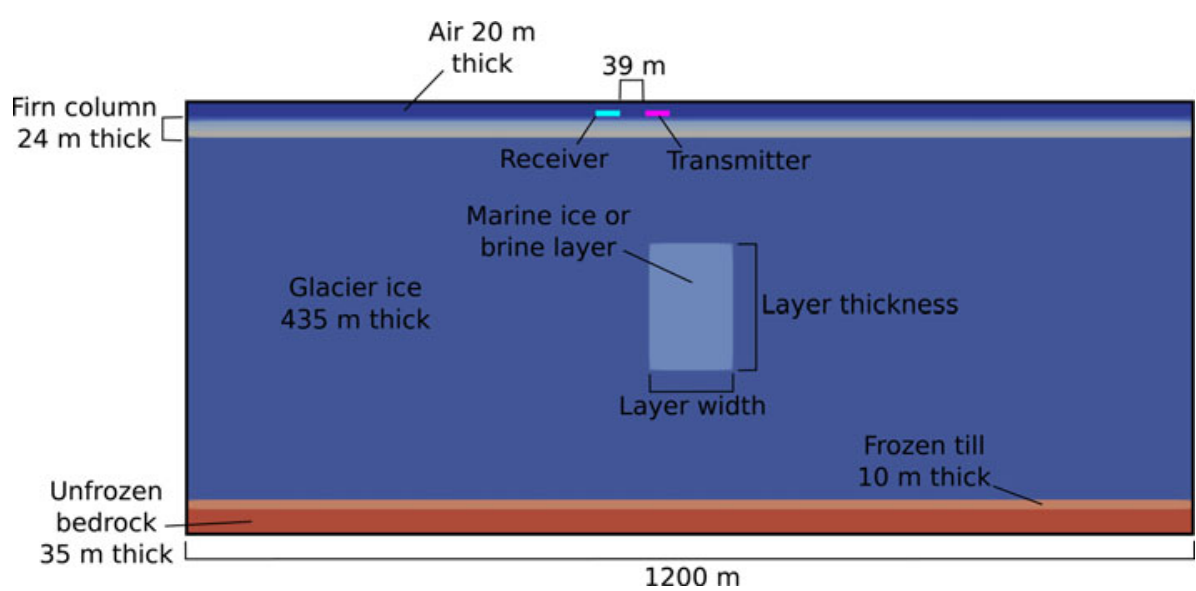

Fig. 8. (a) Results of the return power at the bed for each member of gprMax model ensemble, minus the control run. Return power values are averaged over 10 vertical meters and 50 horizontal meters at the bed in the center of the domain. We consider values $\leq-30 \mathrm{~dB}$ to be consistent with our observations. Marker size corresponds to layer thickness: For marine ice, small $=10 \mathrm{~m}$; medium $=150 \mathrm{~m}$; large $=305 \mathrm{~m}$. For brine layer, small =1 m; large $=10 \mathrm{~m}$. (b) Return power minus control run for ensemble members with width $=100 \mathrm{~m}$ as a function of depth. Power is averaged over 50 horizontal meters spanning the domain center and smoothed using a $10 \mathrm{~m}$ running average. Reflection multiples are indicated by black arrows. Horizontal grey bar indicates the location of the ice rise bed. Colors are the same as those in panel (a). Different layer thicknesses are not denoted because material properties have the strongest control on the results. Results of the full ensemble are shown in the Appendix (Fig. 10).
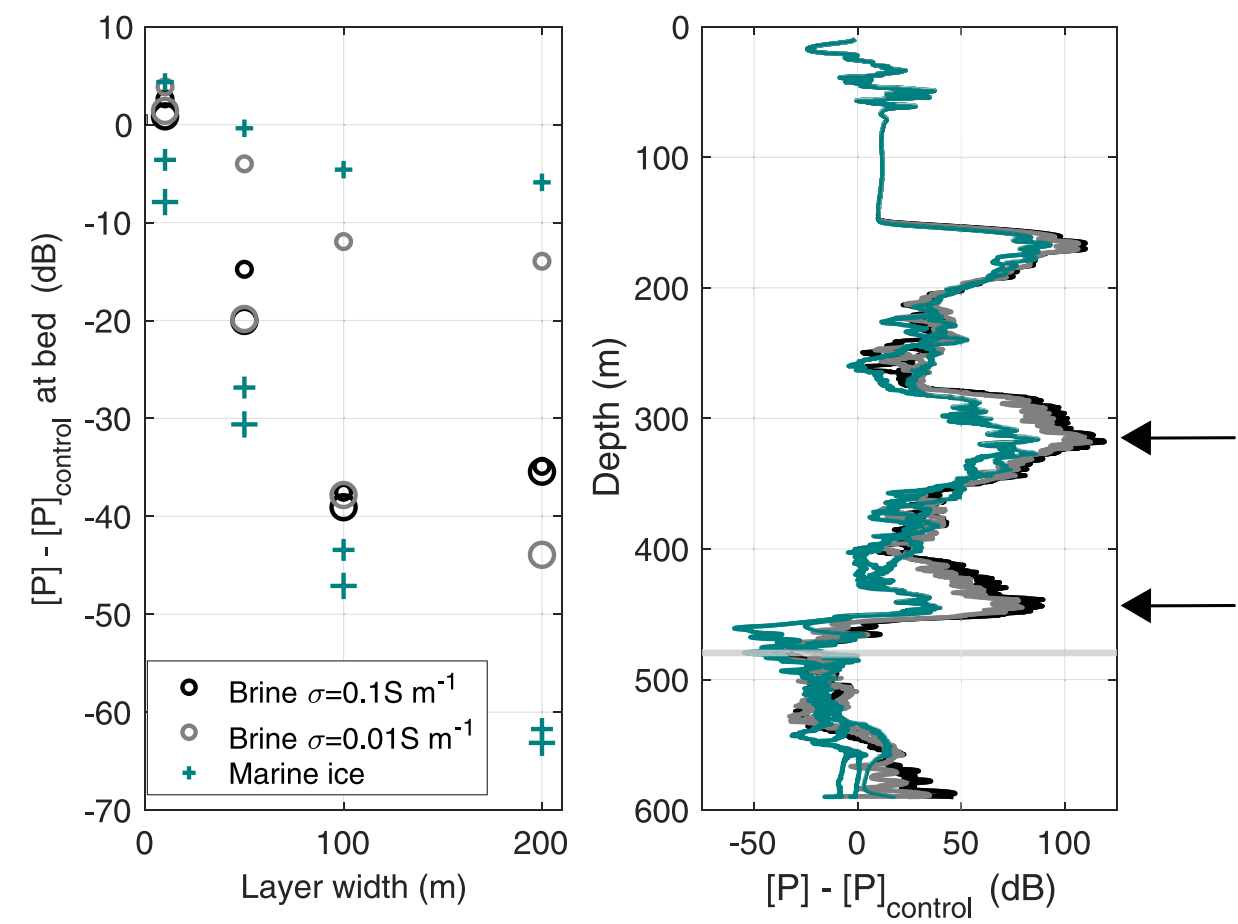

observations of diffraction hyperbolas overlying a loss of bed echo to be most consistent with the presence of marine ice deposits hundreds of meters thick and up to (and perhaps exceeding) $1.5 \mathrm{~km}$ wide (e.g. Fig. $4 \mathrm{~d}$ ). While this is a large amount of marine ice, it is reasonable by comparison with the thick packages of marine ice accreted within and beneath modern ice shelves. Bands of marine ice hundreds of meters thick and continuous for up to hundreds of kilometers in extent have been detected at the base of ice shelves (Thyssen and others, 1993; Fricker and others, 2001) and within suture zones (e.g. Craven and others, 2009; Jansen and others, 2013).

\section{Discussion}

Figure 9 illustrates possible processes that could cause the marine ice structures observed in our radar surveys and modeled above. Three observations distinguish between former basal crevasses and former rifts in our data:

(1) Features that we determine to be former rifts coincide with Layers $\mathrm{A}$ and $\mathrm{B}$, which we take to mark the transitions from shelf and/or streaming ice to locally accumulated ice (see Section 4). Basal crevasses are detected below these layers and did not penetrate the full ice thickness. The tops of rifts fill with snow, sea ice and icebergs, while marine ice accretion within rifts occurs from the top downwards as melting of the rift walls drives convection (Khazendar and Jenkins, 2003). The freezing-point dependence on pressure causes buoyant plumes of supercooled meltwater to refreeze at shallower depths within crevasses and rifts (Lewis and Perkin, 1986).

(2) The features we identify as marine ice-filled rifts do not exhibit down-warping of internal layers toward the stacks of hyperbolas, while those identified as basal crevasses are often flanked by down-warping internal reflectors on either side (Fig. 2c). Basal crevasses often form at the apexes of basal melt channels (Vaughan and others, 2012), and these channels would have collapsed after the ice shelf grounded and the ice rise thickness exceeding hydrostatic equilibrium, causing down-warping of internal layers (Fig. 9). We note that if rifts are not filled completely with marine ice, the collapse of the unfilled bottom of the rift after grounding would cause similar down-warping of internal layers. However, we do not observe down-warping of layers toward features that intersect Layer $\mathrm{A}$, so we do not believe this is common at 

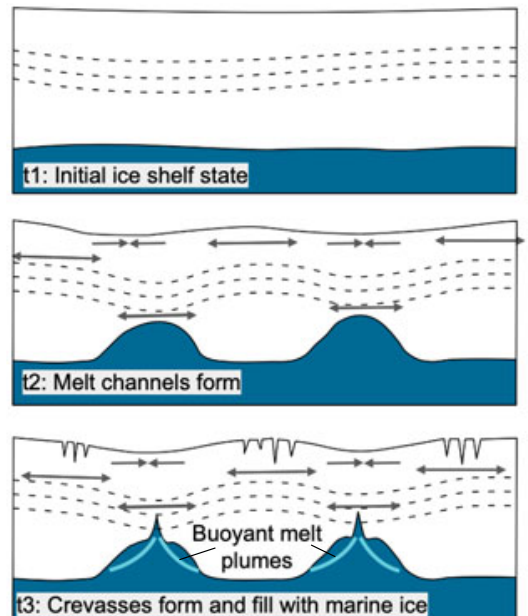

Former ice shelf surface Local accumulation
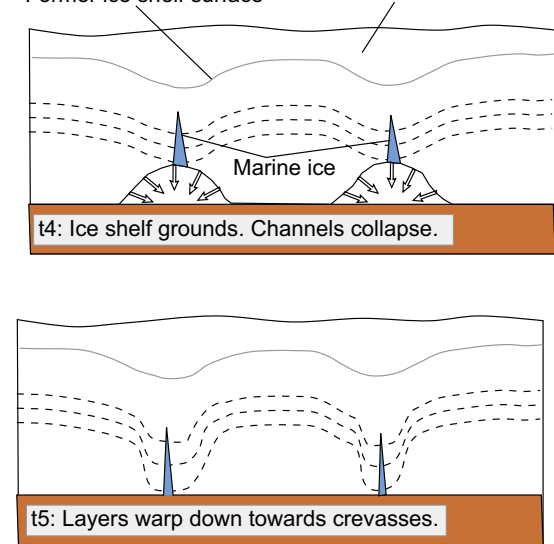

b

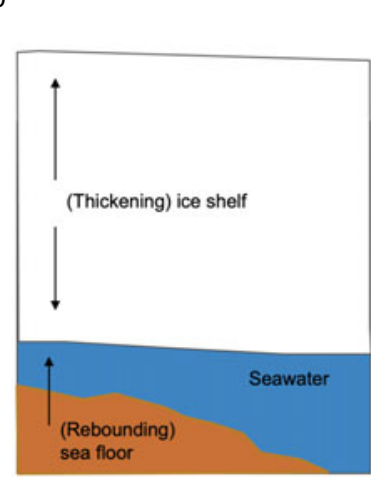

t1: Thickening ice shelf and/or rebounding seafloor cause re-grounding.

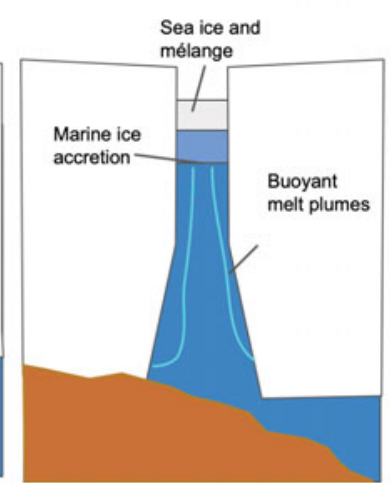

t2: Rifting at edge of grounded ice. Rift begins to fill with marine ice and melange.

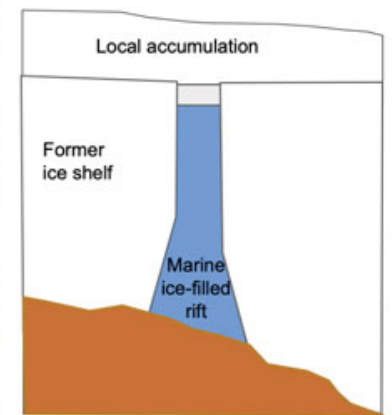

t3: Continued rebound, snow accumulation, and/or dynamic thickening incorporate rifted block and marine ice-filled rift into ice rise.
Fig. 9. Interpretation of processes that could cause the structures observed in our radar surveys. (a) Basal melt channels in an ice shelf causing flexure and crevassing (modified from Vaughan and others, 2012). Black arrows show direction and relative magnitudes of deviatoric stresses. Crevasses fill with marine ice and collapse of basal melt channels after grounding causes downwarping of internal layers toward filled crevasses, such as those seen in Figure 2c. (b) Ice shelf rift filling with marine ice (modified from Khazendar and Jenkins, 2003) and being incorporated into grounded ice.
CIR. This is consistent with the complete infilling of rifts with marine ice on the modern Larsen $\mathrm{C}$ ice shelf (Jansen and others, 2013; Kulessa and others, 2014).

(3) Rifts are more laterally extensive than basal crevasses, and are thus associated with more extensive loss of the bed echo (e.g. Fig. $4 d$ ).

The offset layers labeled in Zone 3 in Figures 3, 4a support the interpretation that the largest regions of lost bed echo are caused by former rifts in the ice shelf. Two sets of internal reflecting horizons at $\sim-200$ and $-300 \mathrm{~m}$ elevation are clearly offset between these blocks, as from differential motion across a fault. We interpret these faults to be former rifts in the ice shelf, as we also find above areas of missing bed reflection (e.g. at $-1 \mathrm{~km}$ in Fig. $4 \mathrm{a}$ ). The apparent dip of these offset layers suggests deformation due to vertical shear. Although there is no detectable offset in Layer A across these faults, the deeper layers are significantly offset. Therefore, the differential motion that caused the offset of these layers must have occurred before the establishment of Layer A. This could be due to irregular melting of the base and/or sides of the rifted blocks while they were still part of the ice shelf. We interpret the continuity of Layer A across the top of these blocks to indicate that they were incorporated into the grounded part of the ice rise over a relatively short span of time, and possibly at the same time.

Our radar surveys reveal that CIR contains abundant marine ice, which likely accreted within rifts and basal crevasses in the Ross Ice Shelf shortly after it re-grounded at this site. Similar complex basal structures beneath the Ross Ice Shelf have been detected by radar (Jezek and others, 1979; Jezek and Bentley, 1983). It is possible that marine ice deposits within slow-flowing grounded ice may be common in West Antarctica due to the late Holocene re-advance of the grounding line to its current configuration (Kingslake and others, 2018). Matsuoka and others (2009) identified a feature they interpreted to be caused by accreted marine ice in crevasses near a former grounding line of Kamb Ice Stream; radar-detected basal crevasses near that feature (Catania and others, 2006) may also contain marine ice. It is possible that marine ice exists within relict basal crevasses identified at other locations around Antarctica, such as the Henry Ice Rise (Kingslake and others, 2018; Wearing and Kingslake, 2019). Basal crevasses in slow-moving grounded ice creep shut quickly (van der Veen, 1998); unless some material other than glacier ice fills the crevasses to create a dielectric contrast, it is unlikely they could be detected by radar after closing. The tilting of the crevasses within Henry Ice Rise (Kingslake and others, 2018; Wearing and Kingslake, 2019) especially indicates that these are not currently open basal crevasses because the shear deformation that tilted them would also have acted to close them (van der Veen, 1998). Whether or not they are filled with enough marine ice (or another material) to be important to ice dynamics is unclear.

Thick layers of marine ice accrete at the bottom of ice shelves and within suture zones, with maximum estimated thicknesses of up to $350 \mathrm{~m}$ (Thyssen and others, 1993; Grosfeld and others, 1998; Fricker and others, 2001). However, accreted marine ice is $<10 \mathrm{~m}$ thick at the base of the modern Ross Ice Shelf (Neal, 1979; Zotikov and others, 1980), and we do not detect a continuous basal layer in our data. We thus attribute the formation of 
marine ice at CIR to localized processes such as refreezing of buoyant melt plumes in rifts and basal crevasses (Fig. 9) (Khazendar and Jenkins, 2003), rather than to large-scale oceanographic conditions extensive beneath the whole Ross Ice Shelf. Marine ice deposits in former basal crevasses have been documented in icebergs calved from the Amery Ice Shelf in East Antarctica (Warren and others, 1993, 2019). The marine ice in these icebergs was found to be rich in organic matter and iron, indicating active biology beneath the ice shelf. It is possible that the marine ice within CIR contains an archive of biological conditions beneath the Ross Ice Shelf more than a millennium ago.

The marine ice within CIR may have played a significant part in its evolution by healing ruptures formed during the grounding events, thereby strengthening and consolidating the floating ice shelf (Rignot and MacAyeal, 1998) and dynamically coupling it to the grounded ice rise. Such strengthening has been documented at the Filchner-Ronne, Brunt/Stancolm-Wills and Larsen C ice shelves (Rignot and MacAyeal, 1998; Holland and others, 2009; Khazendar and others, 2009; Jansen and others, 2013); marine ice in rifts may have played a role in preventing Larsen $C$ from disintegrating in the same fashion as Larsen B (Kulessa and others, 2014). In the Brunt Ice Shelf, an ice mélange consisting partially of marine ice binds together rift-bounded blocks of glacier ice, making the ice shelf effectively a series of icebergs and ice tongues that have been sutured together (King and others, 2018). The same may have been true locally during the formation of CIR, where marine ice accretion could have connected the grounded ice rise with the ice shelf across shear and rift zones, increasing the dynamical coupling of the ice rise to the Ross Ice Shelf and increasing its buttressing effect on the grounded ice-sheet upstream. Marine ice within fractures may also have inhibited rift propagation, thereby supporting the integrity of the ice shelf (Jansen and others, 2013; Larour and others, 2004; Kulessa and others, 2014, 2019). We cannot state definitively whether the rifts existed in the ice shelf before the grounding of CIR, but the rifted zone at the downstream CIR (Fig. 1b) indicates that they likely formed around the ice rise during the initial grounding event. Thus, our observations show that ice rises are able to incorporate heavily fractured and disconnected portions of the surrounding ice shelf into the grounded ice as they grow, and that marine ice formation within those fractures is likely an important part of that process.

Kamb, Mercer and Whillans Ice Streams experienced significant changes in velocity over the past millennium (Catania and others, 2012). It is possible that there was a causal relationship between these changes and the grounding/freeze-on events that our data reveal occurred at CIR. The complex evolution of CIR is broadly consistent with the century-scale changes in ice flux upstream. The ages of the grounding events at $\sim 1100$ and $\sim 580 \mathrm{yr}$ BP derived from borehole thermometry (Bindschadler and others, 1990) would likely be affected by the presence of the large marine ice deposits we reveal here, which could have created a very different initial temperature state than assumed in their model. Thus, the timing of these events may have been similar to the timing of the stagnation and reactivation of Whillans Ice Stream $\sim 860$ and $\sim 450 \mathrm{yr}$ BP, respectively. The stagnation of Kamb Ice Stream $\sim 200 \mathrm{yr} B P$ is also roughly coincident with Bindschadler and others' (1990) estimate of the final freeze-on of the shallow ridge at CIR $130 \mathrm{yr}$ BP. However, relationships between the timing of grounding and ice-stream activity remain speculative.

\section{Conclusions}

We mapped englacial structures within CIR using two radar systems operating at 7 and $750 \mathrm{MHz}$ center frequencies. Three bright reflective horizons (Layers A, B, C) are concomitant with the tops of the strongest diffraction hyperbolas and the shallowest undisturbed locally accumulated ice. We interpret these horizons to delineate three distinct dynamic events that suggest the evolution of the ice rise was more complex than has been documented to-date. Waveform modeling and geometric arguments suggest that the diffraction hyperbolas that are ubiquitous in the central region of the ice rise are caused by marine ice deposits within former rifts and basal crevasses. The former grounding line of CIR - now incorporated into grounded ice - may still be visible as a surface lineation in MODIS imagery (Haran and others, 2014).

Our surveys confirm that CIR is not a remnant of the expanded ice sheet of the last glacial period, but rather formed when the Ross Ice Shelf re-grounded locally. The lower one-half to two-thirds of the ice column consists of former Ross Ice Shelf ice, while the rest has formed from local accumulation. This is consistent with histories inferred by Bindschadler and others (1990), Bindschadler (1993), Fahnestock and others (2000), and Hulbe and Fahnestock $(2004,2007)$ but represents the first confirmation using local geophysical measurements since the borehole thermometry of Bindschadler and others (1990). Marine ice accretion likely acted to reduce further ice fracturing, and to increase dynamic coupling between the grounded ice and the surrounding ice shelf (Khazendar and others, 2009), thereby enhancing its buttressing of Whillans, Mercer and Kamb Ice Streams.

Acknowledgements. This work was supported by NSF grant 1443356 to H.C. and M.K., and grant 1443552 to J.P.W. We thank Maurice Conway and Jade Cooley for assistance in the field. We also thank Antarctic Support Contract, the Air National Guard and Ken Borek Air for logistical support. The Polar Geospatial Center provided high-resolution images for planning our fieldwork. The $750 \mathrm{MHz}$ UHF radar system was provided by CReSIS; we also acknowledge the use of their software, which was generated with support from the State of Kansas, NASA grant NNX16AH54G and NSF grant ACI-1443054. UNAVCO provided GPS equipment and support. We thank Nick Holschuh, Knut Christianson, John Stone, Ed Waddington, Joseph MacGregor, Jonathan Kingslake and Martin Wearing for fruitful discussions, and Richard Hindmarsh for motivating and guiding aspects of this study. We also thank Bernd Kulessa, Frank Pattyn and two anonymous reviewers for insights and suggestions that greatly improved this manuscript. UW $7 \mathrm{MHz}$ and CReSIS $750 \mathrm{MHz}$ radar data and metadata are available at US Antarctic Program Data Center page: http://www.usap-dc.org/view/project/p0010026.

\section{References}

Arcone SA (1995) Numerical studies of the radiation patterns of resistively loaded dipoles. Journal of Applied Geophysics 33(1-3), 39-52. doi: 10.1016/0926-9851(95)90028-4.

Arcone SA and 5 others (2016) Ground-penetrating radar profiles of the McMurdo Shear Zone, Antarctica, acquired with an unmanned rover: interpretation of crevasses, fractures, and folds within firn and marine ice. Geophysics 81(1), WA21-WA34. doi: 10.1190/geo2015-0132.1.

Badgeley JA and 6 others (2017) An englacial hydrologic system of brine within a cold glacier: Blood Falls, McMurdo Dry Valleys, Antarctica. Journal of Glaciology 63(239), 387-400. doi: 10.1017/jog.2017.16.

Bindschadler R (1993) Siple Coast Project research of Crary Ice Rise and the mouths of Ice Streams B and C, West Antarctica: review and new perspectives. Journal of Glaciology 39, 538-552.

Bindschadler RA, Roberts EP and Iken A (1990) Age of Crary Ice Rise, Antarctica, determined from temperature-depth profiles. Annals of Glaciology 14, 13-16.

Campbell S, Courville Z, Sinclair S and Wilner J (2017) Brine, englacial structure and basal properties near the terminus of McMurdo Ice Shelf, Antarctica. Annals of Glaciology 58(74), 1-11.

Catania GA, Conway H, Raymond CF and Scambos TA (2006) Evidence for floatation or near floatation in the mouth of Kamb Ice Stream, West Antarctica, prior to stagnation. Journal of Geophysical Research: Earth Surface 111(F1), 1-10. doi: 10.1029/2005JF000355. 
Catania G, Hulbe C, Conway H, Scambos TA and Raymond CF (2012) Variability in the mass flux of the Ross ice streams, West Antarctica, over the last millennium. Journal of Glaciology 58(210), 741-752. doi: 10.3189/ 2012JoG11J219.

Christianson K and 6 others (2016) Basal conditions at the grounding zone of Whillans Ice Stream, West Antarctica, from ice-penetrating radar. Journal of Geophysical Research Earth Surface 121(11), 1954-1983. doi: 10.1002/ 2015JF003806

Craven M, Allison I, Fricker HA and Warner R (2009) Properties of a marine ice layer under the Amery Ice Shelf, East Antarctica. Journal of Glaciology 55(192), 717-728.

Das I and 11 others (2020) Multidecadal basal melt rates and structure of the Ross Ice Shelf, Antarctica, using airborne ice penetrating radar. Journal of Geophysical Research: Earth Surface 125(3), 1-20. doi: 10.1029/2019JF005241.

Fahnestock MA, Scambos TA, Bindschadler RA and Kvaran G (2000) A millennium of variable ice flow recorded by the Ross Ice Shelf. Antarctica. Journal of Glaciology 46(155), 652-664

Favier L and Pattyn F (2015) Antarctic ice rise formation, evolution, and stability. Geophysical Research Letters 42(11), 4456-4463. doi: 10.1002/2015GL064195.

Fretwell P and 59 others (2013) Bedmap2: improved ice bed, surface and thickness datasets for Antarctica. The Cryosphere 7(1), 375-393. doi: http://dx.doi.org/10.5194/tc-7-375-2013.

Fricker HA, Popov S, Allison I and Young N (2001) Distribution of marine ice beneath the Amery Ice Shelf. Geophysical Research Letters 28(11) 2241-2244. doi: 10.1029/2000GL012461.

Fujita S and 6 others (1999) Nature of radio echo layering in the Antarctic Ice Sheet detected by a two-frequency experiment. Journal of Geophysical Research 104(B6), 13013-13024. doi: 10.1029/1999JB900034.

Gades AM, Raymond CF, Conway H and Jacobel RW (2000) Bed properties of Siple Dome and adjacent ice streams, West Antarctica, inferred from radio-echo sounding measurements. Journal of Glaciology 46(152), 88-94. doi: $10.3189 / 172756500781833467$

Goldberg D, Holland DM and Schoof C (2009) Grounding line movement and ice shelf buttressing in marine ice sheets. Journal of Geophysical Research 114(F4), F04026. doi: 10.1029/2008JF001227.

Greene CA, Gwyther DE and Blankenship DD (2017) Antarctic mapping tools for Matlab. Computers \& Geosciences 104, 151-157. doi: 10.1016/j. cageo.2016.08.003.

Grima C and 6 others (2016) Radar detection of the brine extent at McMurdo Ice Shelf, Antarctica, and its control by snow accumulation. Geophysical Research Letters 43(13), 7011-7018. doi: 10.1002/2016GL069524.

Grosfeld K and 5 others (1998) Marine ice beneath Filchner Ice Shelf Evidence from a multi-disciplinary approach. In Jacobs S and Weiss R (eds), Ocean, Ice and Atmosphere Interactions at the Antarctic Continental Margin, vol. 75. Antarct Res Ser, Washington, DC: AGU, pp. 319-339.

Haran T, Bohlander J, Scambos T, Painter T and Fahnestock M (2014) MODIS Mosaic of Antarctica 2008-2009 (MOA2009) image map. Boulder, Colorado USA, National Snow and Ice Data Center 10, N5KP8037.

Herron MM and Langway CC (1980) Firn densification: an empirical model. Journal of Glaciology 25(93), 373-385. doi: 10.3189/S0022143000015239.

Holland PR, Corr HFJ, Vaughan DG, Jenkins A and Skvarca P (2009) Marine ice in Larsen Ice Shelf. Geophysical Research Letters 36(11), L11604. doi: 10.1029/2009GL038162.

Holschuh N, Christianson K and Anandakrishnan S (2014) Power loss in dipping internal reflectors, imaged using ice-penetrating radar. Annals of Glaciology 55(67), 49-56. doi: 10.3189/2014AoG67A005.

Howat IM, Porter C, Smith BE, Noh M-J and Morin P (2019) The reference elevation model of Antarctica. The Cryosphere 13(2), 665-674.

Hulbe CL and Fahnestock MA (2004) West Antarctic ice-stream discharge variability: mechanism, controls and pattern of grounding-line retreat. Journal of Glaciology 50(171), 471-484

Hulbe C and Fahnestock M (2007) Century-scale discharge stagnation and reactivation of the Ross ice streams, West Antarctica. Journal of Geophysical Research: Earth Surface 112(F3), 1-11.

Jacobel RW, Christianson K, Wood AC, Dallasanta KJ and Gobel RM (2014) Morphology of basal crevasses at the grounding zone of Whillans Ice Stream, West Antarctica. Annals of Glaciology 55(67), 57-63. doi: 10. 3189/2014AoG67A004

Jansen D, Luckman A, Kulessa B, Holland PR and King EC (2013) Marine ice formation in a suture zone on the Larsen C Ice Shelf and its influence on ice shelf dynamics. Journal of Geophysical Research: Earth Surface 118(3), 1628-1640. doi: 10.1002/jgrf.20120.
Jezek KC and Bentley CR (1983) Field studies of bottom crevasses in the Ross Ice Shelf. Antarctica. Journal of Glaciology 29(101), 118-126

Jezek KC, Bentley CR and Clough JW (1979) Electromagnetic sounding of bottom crevasses on the Ross Ice Shelf. Antarctica. Journal of Glaciology 24(90), 321-330

Khazendar A and Jenkins A (2003) A model of marine ice formation within Antarctic ice shelf rifts. Journal of Geophysical Research: Oceans 108(C7), 113. doi: 10.1029/2002JC001673.

Khazendar A, Rignot E and Larour E (2009) Roles of marine ice, rheology, and fracture in the flow and stability of the Brunt/Stancomb-Wills Ice Shelf. Journal of Geophysical Research 114(F4), 1-9. doi: 10.1029/ 2008JF001124.

Khazendar A, Tison J-L, Stenni B, Dini M and Bondesan A (2001) Significant marine-ice accumulation in the ablation zone beneath an Antarctic ice shelf. Journal of Glaciology 47(158), 359-368. doi: 10.3189/ 172756501781832160.

King EC, Rydt JD and Gudmundsson GH (2018) The internal structure of the Brunt Ice Shelf from ice-penetrating radar analysis and implications for ice shelf fracture. The Cryosphere 12(10), 3361-3372. doi: https://doi. org/10.5194/tc-12-3361-2018.

Kingslake J and 9 others (2018) Extensive retreat and re-advance of the West Antarctic Ice Sheet during the Holocene. Nature, 558, 430-434. doi: 10. 1038/s41586-018-0208-x.

Kulessa B and 10 others (2019) Seawater softening of suture zones inhibits fracture propagation in Antarctic ice shelves. Nature Communications 10 (1), 5491. doi: 10.1038/s41467-019-13539-x.

Kulessa B, Jansen D, Luckman AJ, King EC and Sammonds PR (2014) Marine ice regulates the future stability of a large Antarctic ice shelf. Nature Communications 5, 1-7. doi: 10.1038/ncomms4707.

Larour E, Rignot E and Aubry D (2004) Processes involved in the propagation of rifts near Hemmen Ice Rise, Ronne Ice Shelf, Antarctica. Journal of Glaciology 50(170), 329-341. doi: 10.3189/172756504781829837.

Leuschen C, Gogineni S and Tammana D (2000) SAR processing of radar echo sounder data. Geoscience and Remote Sensing Symposium, 2000. Proceedings. IGARSS 2000. IEEE 2000 International, vol. 6, pp. 2570-2572. doi: 10.1109/IGARSS.2000.859643.

Lewis CS (2015) Ice Shelf Melt Rates and 3D Imaging (PhD thesis). University of Kansas.

Lewis C and 6 others (2015) Airborne fine-resolution UHF radar: an approach to the study of englacial reflections, firn compaction and ice attenuation rates. Journal of Glaciology 61(225), 89-100. doi: 10.3189/2015JoG14J089.

Lewis EL and Perkin RG (1986) Ice pumps and their rates. Journal of Geophysical Research: Oceans 91(C10), 11756-11762

Looyenga H (1965) Dielectric constants of heterogeneous mixtures. Physica 31 (3), 401-406. doi: 10.1016/0031-8914(65)90045-5.

Lux F (1993) Models proposed to explain the electrical conductivity of mixtures made of conductive and insulating materials. Journal of Materials Science 28(2), 285-301.

MacAyeal DR, Bindschadler RA, Stephenson S, Shabtaie S and Bentley CR (1987) Force, mass, and energy budgets of the Crary Ice Rise complex, Antarctica. Journal of Glaciology 33, 218-230.

MacAyeal R, Bindschadler RA, Stephenson S, Shabtaie S and Bentley CR (1989) Correction to: force, mass, and energy budgets of the Crary Ice Rise complex, Antarctica. Journal of Glaciology 35(119), 151-152. doi: 10. 3189/S0022143000004901.

Matsuoka K and 19 others (2015) Antarctic ice rises and rumples: their properties and significance for ice-sheet dynamics and evolution. Earth-Science Reviews 150, 724-745. doi: 10.1016/j.earscirev.2015.09.004.

Matsuoka K, Gades A, Conway H, Catania G and Raymond CF (2009) Radar signatures beneath a surface topographic lineation near the outlet of Kamb Ice Stream and Engelhardt Ice Ridge, West Antarctica. Annals of Glaciology 50(51), 98-104. doi: 10.3189/172756409789097595.

Morey RM, Kovacs A and Cox GF (1984) Electromagnetic properties of sea ice. Cold Regions Science and Technology 9(1), 53-75.

Morse DL and Waddington ED (1994) Recent survey of brine infiltration in McMurdo Ice Shelf, Antarctica. Annals of Glaciology 20, 215-218.

Neal CS (1979) The dynamics of the Ross Ice Shelf revealed by radio echosounding. Journal of Glaciology 24(90), 295-307. doi: 10.3198/1979JoG2490-295-307.

Rignot E and MacAyeal DR (1998) Ice-shelf dynamics near the front of the Filchner - Ronne Ice Shelf, Antarctica, revealed by SAR interferometry. Journal of Glaciology 44(147), 405-418. doi: 10.3189/S0022143000002732. 
Rodriguez-Morales F and 17 others (2014) Advanced multifrequency radar instrumentation for polar research. IEEE Transactions on Geoscience and Remote Sensing 52(5), 2824-2842. doi: 10.1109/TGRS.2013.2266415.

Still H, Campbell A and Hulbe C (2018) Mechanical analysis of pinning points in the Ross Ice Shelf, Antarctica. Annals of Glaciology 60(78), $1-10$.

Thomas RH (1975) Liquid brine in ice shelves. Journal of Glaciology 14(70), $125-136$.

Thomas RH (1979) Ice shelves: a review. Journal of Glaciology 24(90), 273-286. doi: 10.3198/1979JoG24-90-273-286.

Thyssen F, Bombosch A and Sandhäger H (1993) Elevation, ice thickness and structure mark maps of the central part of the Filchner-Ronne Ice Shelf. Polarforschung 62(1), 17-26.

Tinto KJ and 30 others (2019) Ross Ice Shelf response to climate driven by the tectonic imprint on seafloor bathymetry. Nature Geoscience 12(6), 441. doi: 10.1038/s41561-019-0370-2.

van der Veen C ( 1998) Fracture mechanics approach to penetration of surface crevasses on glaciers. Cold Regions Science and Technology 27(1), 31-47. doi: 10.1016/S0165-232X(97)00022-0.
Vaughan DG and 8 others (2012) Subglacial melt channels and fracture in the floating part of Pine Island Glacier, Antarctica. Journal of Geophysical Research 117(F3), F03012. doi: 10.1029/2012JF002360.

Warren SG and 5 others (1993) Green icebergs formed by freezing of organic-rich seawater to the base of Antarctic ice shelves. Journal of Geophysical Research: Oceans 98(C4), 6921-6928. doi: 10.1029/92JC02751.

Warren C, Giannopoulos A and Giannakis I (2016) Gprmax: open source software to simulate electromagnetic wave propagation for ground penetrating radar. Computer Physics Communications 209, 163-170. doi: 10.1016/j.cpc.2016.08.020.

Warren SG, Roesler CS, Brandt RE and Curran M (2019) Green icebergs revisited. Journal of Geophysical Research: Oceans 124, 925-938. doi: 10.1029/2018JC014479.

Wearing MG and Kingslake J (2019) Holocene Formation of Henry Ice Rise, West Antarctica, Inferred From Ice-Penetrating Radar. Journal of Geophysical Research: Earth Surface 124(8), 2224-2240

Zotikov IA, Zagorodnov VS and Raikovsky JV (1980) Core drilling through the Ross Ice Shelf (Antarctica) confirmed basal freezing. Science 207(4438), 1463-1465.

\section{Appendix}

\section{Complete ensemble results}

Figure 10.

Fig. 10. Return power relative to control run for each member of the ensemble as a function of depth. Power is averaged over 50 horizontal meters spanning the domain center, and smoothed using a $10 \mathrm{~m}$ running average. The two very strong reflection multiples below the modeled brine layers are not observed in our data, and we thus attribute observed features to marine ice deposits. Horizontal grey bar indicates the location of the ice rise bed.

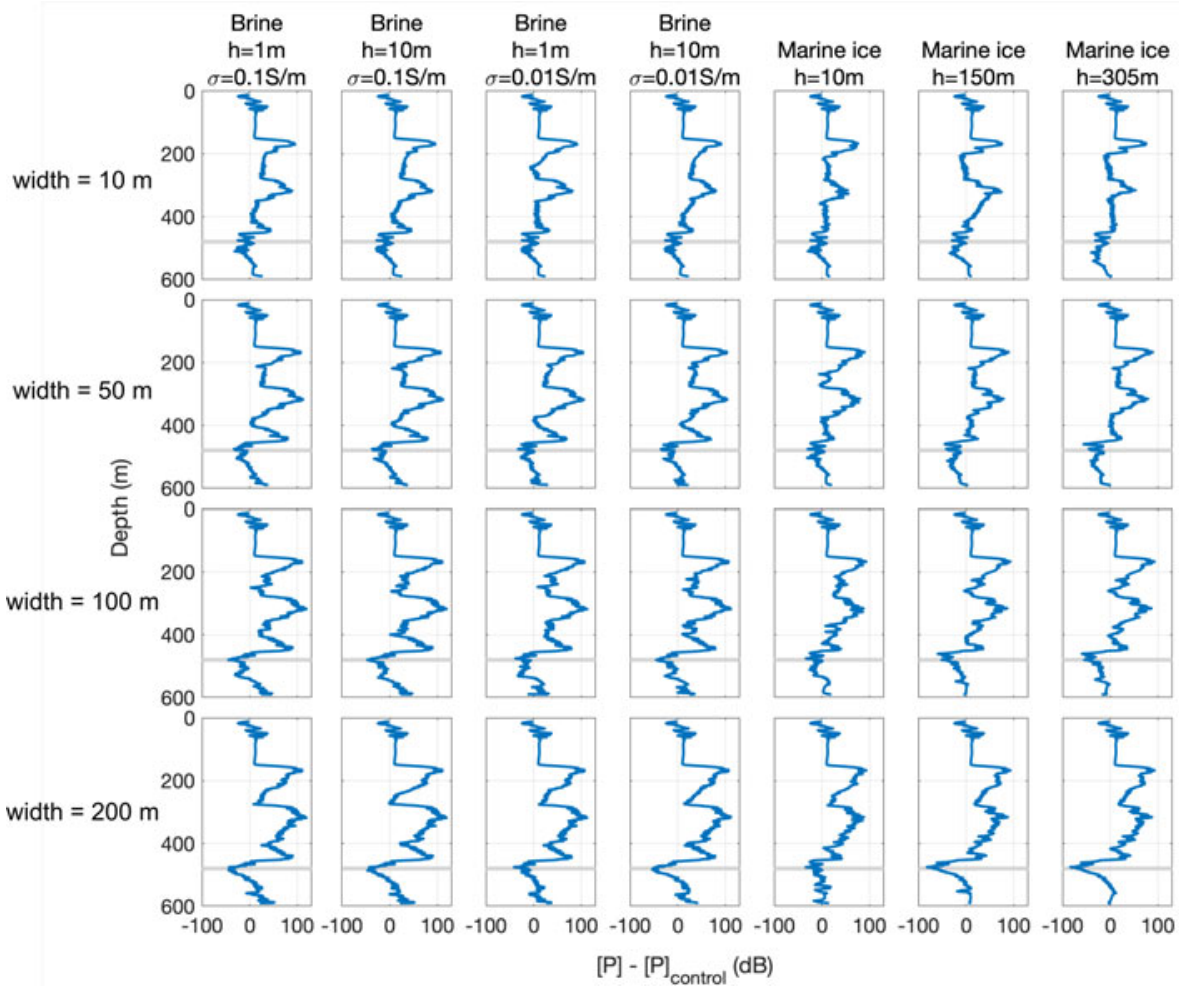

